\title{
Risk Factors for Postoperative Liver Enzyme Elevation After Laparoscopic Gastrectomy for Gastric Cancer
}

\author{
AKIHIKO SANO ${ }^{1}$, KANA SAITO ${ }^{2}$, KENGO KURIYAMA ${ }^{1}$, NOBUHIRO NAKAZAWA ${ }^{1}$, YASUNARI UBUKATA ${ }^{1}$, \\ KEIGO HARA $^{1}$, MAKOTO SAKAI ${ }^{1}$, KYOICHI OGATA ${ }^{1}$, TAKAHARU FUKASAWA ${ }^{2}$, MAKOTO SOHDA ${ }^{1}$, \\ MINORU FUKUCHI ${ }^{2}$, HIROSHI NAITOH ${ }^{2}$, KEN SHIRABE $^{1}$ and HIROSHI SAEKI ${ }^{1}$ \\ ${ }^{1}$ Department of General Surgical Science, Gunma University Graduate School of Medicine, Gunma, Japan; \\ ${ }^{2}$ Department of Surgery, Japan Community Healthcare Organization Gunma Central Hospital, Gunma, Japan
}

\begin{abstract}
Background/Aim: Laparoscopic gastrectomy $(L G)$ is more frequently associated with postoperative liver enzyme elevation (PLEE) than open gastrectomy in phase III clinical trials for Japanese gastric cancer patients. The aim of this study was to determine the risk factors for PLEE after $L G$ for gastric cancer. Patients and Methods: This study enrolled 153 consecutive patients with gastric cancer who underwent LG. The patient characteristics, the liver retraction method [silicone disc (SD) or Nathanson liver retractor (NLR)], and perioperative outcomes were compared between patients with and without PLEE. Results: PLEE was observed in 26 patients (17\%). The patients with $P L E E$ exhibited longer operative times $(p=0.005)$ and more frequent use of the NLR for liver retraction $(p=0.022)$. In the multivariate analysis, liver retraction using the NLR $(p=0.003)$ and aberrant left hepatic artery (ALHA) ligation $(p=0.042)$ were independent risk factors of PLEE. Conclusion: Liver retraction with the $S D$ during $L G$ was shown to be the safer method that is less likely to cause postoperative liver dysfunction. ALHA preservation may contribute to avoiding postoperative liver dysfunction.
\end{abstract}

Laparoscopic gastrectomy (LG) has several advantages over open gastrectomy (OG), including fewer complications, less intraoperative blood loss and postoperative pain, faster recovery of bowel function, shorter hospital stays, and

This article is freely accessible online.

Correspondence to: Akihiko Sano, MD, Ph.D., Department of General Surgical Science, Gunma University Graduate School of Medicine, 3-39-22 Showa-machi, Maebashi, Gunma 371-8511, Japan. Tel: +81 272208224, Fax: +81 27220 8230, e-mail: ak_sano@outlook.jp

Key Words: Postoperative liver enzyme elevation, liver retraction method, aberrant left hepatic artery preserving lymphadenectomy. acceptable long-term outcomes $(1,2)$. Although LG has gained widespread acceptance in recent years as a minimally invasive surgical method, phase III clinical trials have shown that LG is more frequently associated with serum aspartate aminotransferase (AST)/alanine aminotransferase (ALT) elevation than OG (3). Various risk factors for postoperative liver enzyme elevation (PLEE) after LG have been reported, with reduced portal flow caused by the carbon dioxide $\left(\mathrm{CO}_{2}\right)$ pneumoperitoneum being a particular concern (4). According to basic science studies, $\mathrm{CO}_{2}$ pneumoperitoneum markedly decreases total hepatic blood flow by mechanical compression or hypercapnia-induced vasoconstriction (5). However, in a previous study comparing LG and laparoscopy-assisted colectomy, PLEE was only observed after LG, despite the use of $\mathrm{CO}_{2}$ pneumoperitoneum during both procedures (6). This suggests that PLEE after LG may be due to causes other than the $\mathrm{CO}_{2}$ pneumoperitoneum.

Although direct damage to the hepatic parenchyma by mechanical liver retraction and ligation of an aberrant left hepatic artery (ALHA) originating from the left gastric artery (LGA) have been reported to cause PLEE after LG $(6,7)$, the most significant risk factors are still controversial. Therefore, in this study, we retrospectively evaluated clinical data of patients who underwent LG for gastric cancer to determine the risk factors for PLEE.

\section{Patients and Methods}

Ethical approval and informed consent. This study was approved by the ethics committee of Japan Community Healthcare Organization Gunma Central Hospital (approval No. 2018-031-001) and has therefore been performed in accordance with the ethical standards laid down in the 1964 Declaration of Helsinki and its later amendments. All patients provided informed consent to undergo LG prior to surgery.

Patients and data collection. From June 2013 to May 2019, 153 consecutive patients (103 men and 50 women) with gastric cancer underwent LG at Japan Community Healthcare Organization Gunma 

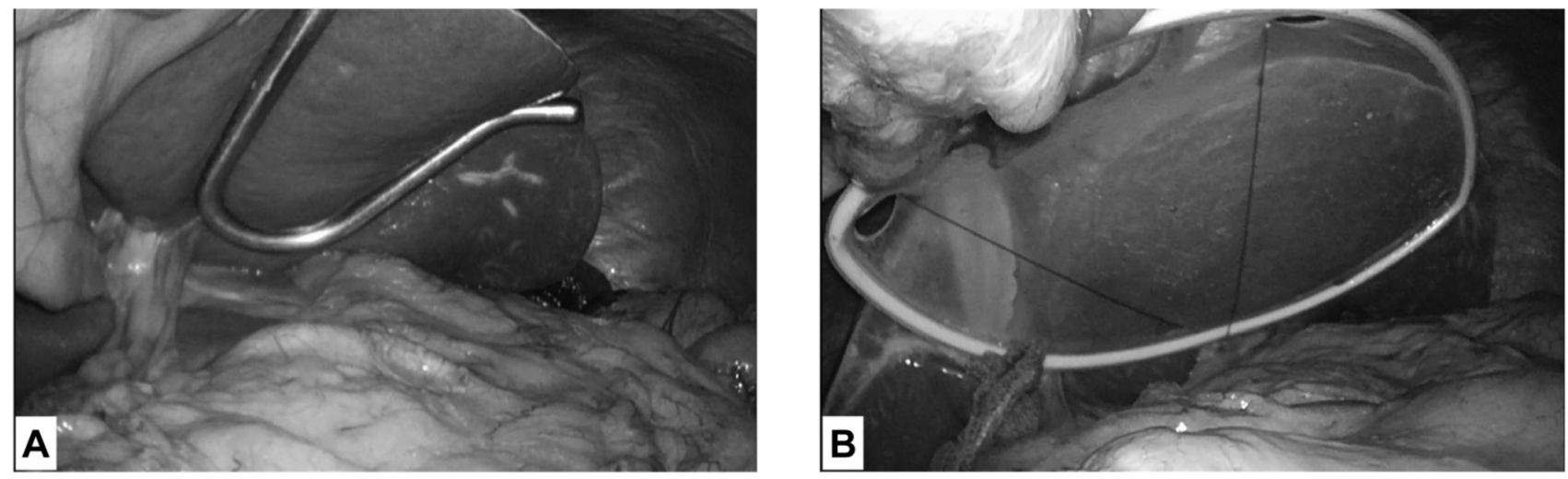

Figure 1. Our liver retraction approaches during laparoscopic gastrectomy: the Nathanson liver retractor (A) and the silicone disc (B).
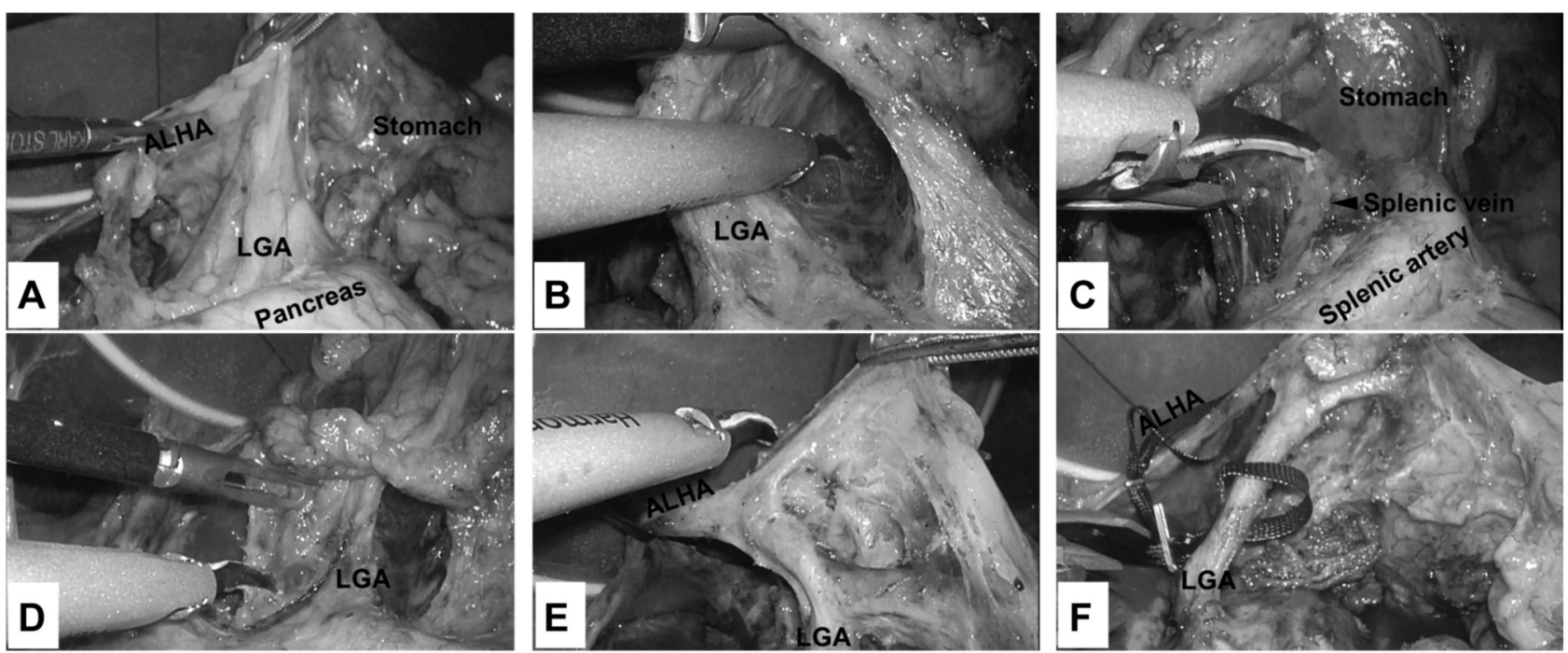

Figure 2. The outline of aberrant left hepatic artery (ALHA) preserving lymphadenectomy around the left gastric artery (LGA). (A) Confirmation of ALHA branching from the LGA. (B) Lymphadenectomy on the left side of the LGA. (C) Lymphadenectomy up to the front of the splenic vein. (D) Lymphadenectomy on the right side of the LGA. (E) ALHA and the branches from the LGA. (F) After completion of ALHA preserving lymphadenectomy around the LGA.

Central Hospital. The histological diagnosis for all patients was adenocarcinoma of the stomach. Clinical evaluation of tumor stage was determined by pre-operative endoscopy and computed tomography (CT). Clinical data were retrospectively collected from the patients' medical records and operation videos. The following data were collected: patient characteristics, including sex, age, body mass index (BMI; $\mathrm{kg} / \mathrm{m}^{2}$ ), and American Society of Anesthesiologists Physical Status Classification (ASA-PS); tumor data, including clinical TNM status and clinical stage; preoperative comorbidities; operative and postoperative results, including operation time, estimated blood loss, specific procedure, liver retraction method, extent of lymph node dissection, number of dissected lymph nodes, status of ALHA, length of hospital stay, postoperative complications, and postoperative liver function tests. Aspartate aminotransferase (AST) and alanine aminotransferase (ALT) were measured preoperatively and on postoperative days $1,3,5$, and 7 . PLEE was defined as the elevation of postoperative AST or ALT levels to $\geq 3$ times the upper limit of normal at least once during the 7-day period after LG. The frequency of PLEE was assessed with respect to the patients' characteristics and preoperative comorbidities. Surgical outcomes and postoperative complications were also compared between patients with and without PLEE. Postoperative morbidities were described according to the Japan Clinical Oncology Group criteria based on the Clavien-Dindo classification (8).

Liver retraction methods. From June 2013 to May 2015, retraction of the left liver lobe was performed using a Nathanson liver retractor (NLR) (Figure 1A) after completing the dissection of lymph nodes along the greater curvature and infrapyloric lymph nodes. The NLR was inserted close to the xiphoid process and placed near the hepatic hilus under the lateral segment of the liver. Since June 2015, we have used the medium-sized silicone disc (SD) (Hakko Co., Ltd., Nagano, 

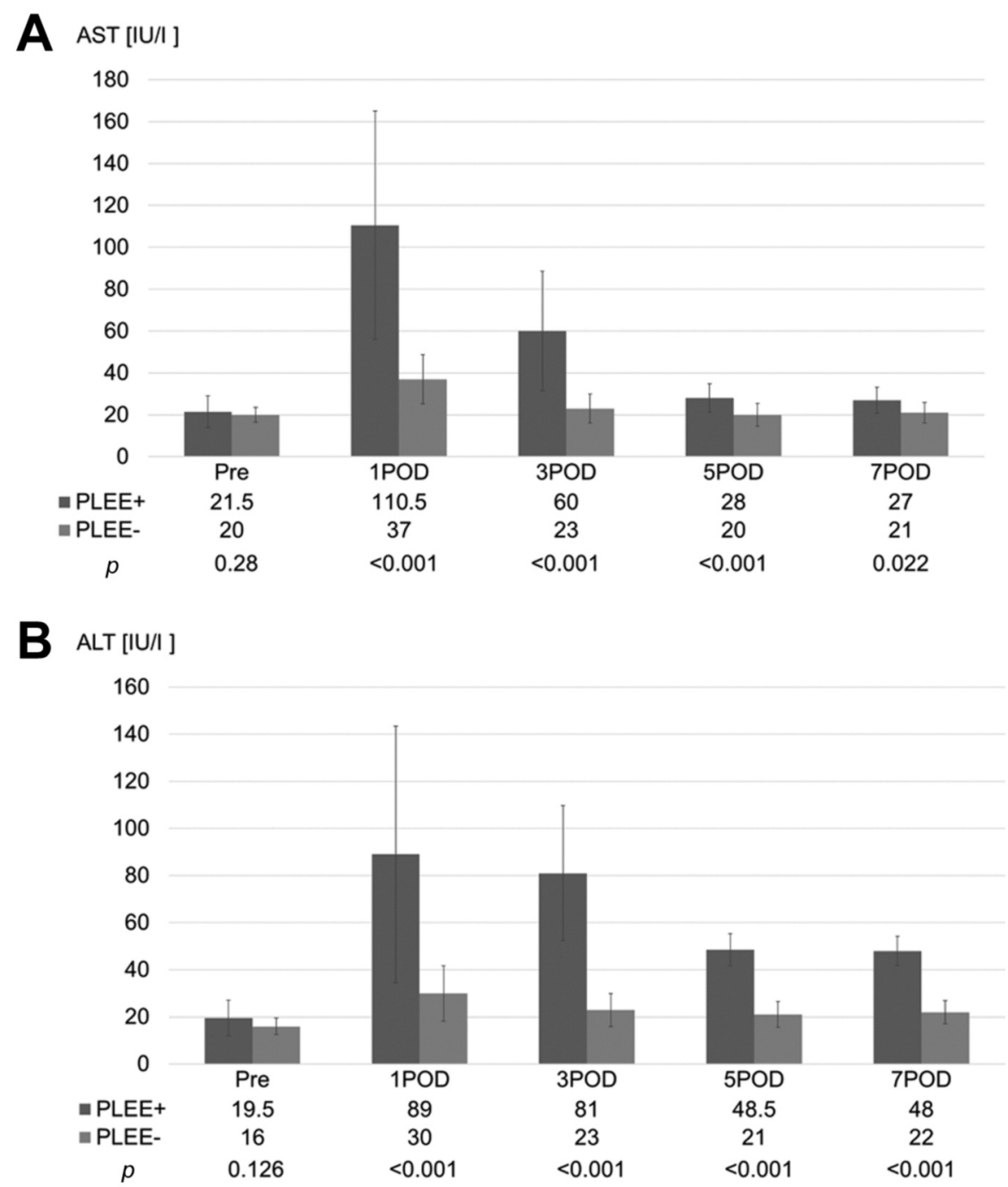

Figure 3. Perioperative change in liver enzyme levels (median, quartile deviation) after laparoscopic gastrectomy for gastric cancer according to the presence of postoperative liver enzyme elevation (PLEE). (A) Aspartate aminotransferase (AST); (B) Alanine aminotransferase (ALT). POD: Postoperative day.

Japan) with a percutaneous stitching nylon thread (Figure 1B) to avoid the incision needed for insertion of the NLR.

Management of the ALHA. The ALHA was ligated to allow for a sufficient lymph node dissection, even if its presence had been detected on preoperative $\mathrm{CT}$ or intraoperative exploration. However, the ALHA was preserved in the following cases: a large ALHA diameter (approximately $\geq 5 \mathrm{~mm}$ as assessed intraoperatively); inability to confirm that the left hepatic artery arises from the proper hepatic artery on preoperative $\mathrm{CT}$; the presence of a common hepatic artery defect (so-called replaced left hepatic artery from the LGA); and when radical lymphadenectomy around the LGA was considered possible with ALHA preservation, as described in a previous report (9). Our procedure of ALHA-preserving lymphadenectomy around the LGA was shown in Figure 2. In exceptional cases, the ALHA was sometimes unintentionally ligated in obese patients because of difficulty of proper identification.
Survival analysis. To investigate the effect of ALHA preserving lymphadenectomy in radical gastrectomy on the curability of gastric cancer, local recurrence rates and overall and recurrence-free survival were analyzed between the patients that underwent typical lymphadenectomy with division of the LGA origin (including ALHA absent and ALHA ligated patients) and those that underwent an ALHA preserving lymphadenectomy.

Statistical analysis. Comparisons were conducted using Fisher's exact test for categorical variables and Mann-Whitney $U$-tests for quantitative variables. A multivariate analysis to identify the risk factors for PLEE was conducted using a logistic regression model that included all variables with $p<0.1$ in the univariate analysis. Survival analysis was performed by the Kaplan-Meier method, with comparison between survival curves performed using the logrank method. Differences were considered significant when the $p$ value was less than 0.05. All data were analyzed using EZR, 
Table I. Comparison of PLEE by each baseline characteristics.

\begin{tabular}{|c|c|c|c|c|c|}
\hline \multirow[t]{2}{*}{ Factor } & \multirow[t]{2}{*}{ Variable } & \multirow[t]{2}{*}{ Total $(n=153)$} & \multicolumn{2}{|c|}{ PLEE } & \multirow[t]{2}{*}{$p$-Value } \\
\hline & & & Present $(n=26)$ & Absent $(n=127)$ & \\
\hline \multirow[t]{2}{*}{ Gender } & Male & 103 & 20 & 83 & \multirow[t]{2}{*}{0.359} \\
\hline & Female & 50 & 6 & 44 & \\
\hline Age, years (Median, range) & & $71(39-90)$ & $69(41-89)$ & $71(39-90)$ & 0.371 \\
\hline BMI (Median, range) $\left[\mathrm{kg} / \mathrm{m}^{2}\right]$ & & $22.9(16.5-31.2)$ & $24.4(18.1-30.2)$ & $22.7(16.5-31.2)$ & 0.051 \\
\hline \multirow[t]{3}{*}{ ASA-PS } & 1 & 14 & 4 & 10 & \multirow[t]{3}{*}{0.227} \\
\hline & 2 & 120 & 21 & 99 & \\
\hline & 3 & 19 & 1 & 18 & \\
\hline \multirow[t]{5}{*}{ Clinical T* } & T1a & 12 & 1 & 11 & \multirow[t]{5}{*}{0.933} \\
\hline & $\mathrm{T} 1 \mathrm{~b}$ & 107 & 19 & 88 & \\
\hline & $\mathrm{T} 2$ & 25 & 5 & 20 & \\
\hline & $\mathrm{T} 3$ & 7 & 1 & 6 & \\
\hline & $\mathrm{T} 4 \mathrm{a}$ & 2 & 0 & 2 & \\
\hline \multirow[t]{3}{*}{ Clinical N* } & No & 139 & 24 & 115 & \multirow[t]{3}{*}{1.000} \\
\hline & N1 & 12 & 2 & 10 & \\
\hline & $\mathrm{N} 2$ & 2 & 0 & 2 & \\
\hline \multirow[t]{5}{*}{ Clinical TNM Stage* } & IA & 114 & 19 & 95 & \multirow[t]{5}{*}{0.585} \\
\hline & IB & 27 & 6 & 21 & \\
\hline & IIA & 6 & 0 & 6 & \\
\hline & IIB & 3 & 1 & 2 & \\
\hline & IIIA & 3 & 0 & 3 & \\
\hline
\end{tabular}

PLEE, Postoperative liver enzyme elevation; BMI, body mass index; ASA-PS, American Society Of Anesthesiologists physical status classification. *TNM classification of the International Union Against Cancer.

which is a freely available easy-to-use software for medical statistics (10).

\section{Results}

Changes in postoperative liver enzyme levels. Of the 153 patients who underwent LG, PLEE developed in 26 (17\%). The perioperative changes in AST and ALT levels in patients with and without PLEE are presented in Figure 3. Serum AST and ALT levels were significantly higher in the PLEE+ group than in the PLEE- group on postoperative days 1, 3, 5 and 7. The AST and ALT levels peaked on postoperatively day 1 and gradually decreased.

Clinical characteristics of patients with and without PLEE. The clinical characteristics of patients with and without PLEE are summarized in Table I. The 153 patients consisted of 103 men and 50 women. The median age and BMI were 71 years and $22.9 \mathrm{~kg} / \mathrm{m}^{2}$, respectively. No significant differences were observed in age, sex, ASA-PS or clinical stage of gastric cancer. The BMI at the time of surgery tended to be high in the PLEE group ( $p=0.051)$. Systemic comorbidities, as shown in Table II, were observed in 143 out of 153 patients (93.5\%). Liver disease as a preoperative comorbidity was significantly more common in the PLEE group ( $p=0.010)$, which included 9 patients with non-alcoholic fatty liver disease, 2 with chronic hepatitis $\mathrm{C}, 1$ with type $\mathrm{C}$ cirrhosis, and 1 with alcoholic fatty liver. All patients were classified as childPugh grade A.

Surgical outcomes. In terms of operative results (Table III), patients with PLEE exhibited longer operative times $(p=0.005)$ and more frequent use of the NLR for liver retraction $(p=0.022)$. Estimated blood loss, operative procedure, and extent of lymph node dissection were not significantly different between the two groups. The postoperative hospital stay in both groups was equivalent, and the occurrence of PLEE did not prolong hospitalization as it tended to subside within approximately 1 week of LG (Figure 3). With the exception of the development of postoperative pancreatic fistula, no relationship between PLEE and other complications was observed (Table IV).

Multivariate analysis of risk factors for PLEE. Univariate analysis demonstrated that five factors (BMI, liver disease as a preoperative comorbidity, operation time, liver retraction using an NLR, and ALHA ligation) were associated with PLEE ( $p<0.1$ for all). These risk factors were further analyzed in the multivariate analysis. In the multivariate analysis, the absence or preservation of the ALHA were combined as the ALHA status. Postoperative 
Table II. Preoperative comorbidity.

\begin{tabular}{|c|c|c|c|c|c|}
\hline \multirow[t]{2}{*}{ Factor } & \multirow[t]{2}{*}{ Variable } & \multirow[t]{2}{*}{ Total $(n=153)$} & \multicolumn{2}{|c|}{ PLEE } & \multirow[t]{2}{*}{$p$-Value } \\
\hline & & & Present $(n=26)$ & Absent $(n=127)$ & \\
\hline \multicolumn{2}{|c|}{ Any comorbidity (systemic) } & $143(93.5 \%)$ & $22(84.6 \%)$ & $121(95.3 \%)$ & 0.067 \\
\hline \multirow[t]{5}{*}{ Liver } & & $13(8.5 \%)$ & $6(23.1 \%)$ & $7(5.5 \%)$ & 0.010 \\
\hline & Non-alcoholic fatty liver disease & 9 & 5 & 4 & \\
\hline & Chronic hepatitis C & 2 & 1 & 1 & \\
\hline & Cirrhosis type $\mathrm{C}$ & 1 & 0 & 1 & \\
\hline & Alcoholic fatty liver & 1 & 0 & 1 & \\
\hline \multicolumn{2}{|c|}{ Diabetes mellitus } & $32(20.9 \%)$ & $5(19.2 \%)$ & $27(21.3 \%)$ & 1.000 \\
\hline \multicolumn{2}{|c|}{ Hypertension } & $70(45.8 \%)$ & $15(57.7 \%)$ & $55(43.3 \%)$ & 0.200 \\
\hline \multicolumn{2}{|c|}{ Cardiac disease } & $24(15.7 \%)$ & $4(15.4 \%)$ & $20(15.7 \%)$ & 1.000 \\
\hline \multicolumn{2}{|c|}{ Respiratory disease } & $20(13.1 \%)$ & $5(19.2 \%)$ & $15(11.8 \%)$ & 0.339 \\
\hline \multicolumn{2}{|c|}{ Cerebral vascular disease } & $13(8.5 \%)$ & $1(3.8 \%)$ & $12(9.4 \%)$ & 0.698 \\
\hline \multicolumn{2}{|c|}{ Past history of abdominal surgery } & $49(32.0 \%)$ & $11(42.3 \%)$ & $38(29.9 \%)$ & 0.251 \\
\hline
\end{tabular}

PLEE, Postoperative liver enzyme elevation.

Table III. Surgical outcomes.

\begin{tabular}{|c|c|c|c|c|c|}
\hline \multirow[t]{2}{*}{ Factor } & \multirow[t]{2}{*}{ Variable } & \multirow[t]{2}{*}{ Total $(n=153)$} & \multicolumn{2}{|c|}{ PLEE } & \multirow[t]{2}{*}{$p$-Value } \\
\hline & & & Present $(n=26)$ & Absent $(n=127)$ & \\
\hline \multicolumn{6}{|l|}{ Operative results } \\
\hline Operation time (min) (Median, range) & & $315(201-530)$ & $345(209-498)$ & $307(201-530)$ & 0.005 \\
\hline Estimated blood loss (ml) (Median, range) & & $20(0-380)$ & $20(0-380)$ & $20(1-350)$ & 0.544 \\
\hline \multirow[t]{4}{*}{ Operative procedure } & LADG & 28 & 9 & 19 & 0.111 \\
\hline & LDG & 96 & 12 & 84 & \\
\hline & LTG & 22 & 4 & 18 & \\
\hline & LPG & 7 & 1 & 6 & \\
\hline \multirow[t]{2}{*}{ Liver retraction method } & NLR & 27 & 9 & 18 & 0.022 \\
\hline & $\mathrm{SD}$ & 126 & 17 & 109 & \\
\hline \multirow{2}{*}{ Extent of lymph node dissection } & $\mathrm{D} 1 / \mathrm{D} 1^{+}$ & 104 & 17 & 87 & 0.819 \\
\hline & D2 & 49 & 9 & 40 & \\
\hline $\begin{array}{l}\text { Number of dissected lymph nodes } \\
\text { (Median, range) }\end{array}$ & & $47(14-101)$ & $47(28-82)$ & $48(14-101)$ & 0.825 \\
\hline Aberrant left hepatic artery (ALHA) & Present/Absent & $54 / 99$ & $11 / 15$ & $43 / 84$ & 0.374 \\
\hline \multirow[t]{3}{*}{ ALHA status } & Ligation & 43 & 11 & 32 & 0.095 \\
\hline & Preservation & 11 & 0 & 11 & \\
\hline & Absent & 99 & 15 & 84 & \\
\hline $\begin{array}{l}\text { Postoperative hospital stay (days) } \\
\text { (Median, range) }\end{array}$ & & $10(7-56)$ & $10(10-33)$ & $10(7-56)$ & 0.250 \\
\hline
\end{tabular}

PLEE, Postoperative liver enzyme elevation; LADG, laparoscopy-assisted distal gastrectomy; LDG, laparoscopic distal gastrectomy; LTG, laparoscopic total gastrectomy; LPG, laparoscopic proximal gastrectomy; NLR, Nathanson liver retractor; SD, silicone disc.

pancreatic fistula, which was correlated with PLEE in the univariate analysis, was excluded from the multivariate analysis as the PLEE likely occurs as a result of the medical treatment of the pancreatic fistula itself. As shown in Table $\mathrm{V}$, liver retraction using an NLR $(p=0.003)$ and ALHA ligation $(p=0.042)$ were independent risk factors for PLEE.
Survival analysis. Since the mean observation period of all 153 patients was 38.2 months, the 3 -year (rather than the 5year) overall and progression-free survival were investigated in this study. There were no significant differences between the ALHA preserving lymphadenectomy group and the typical lymphadenectomy with ligation of the LGA origin group in both overall (100\% vs. 96\%, $p=0.605)$ and 
Table IV. Post-operative complications.

\begin{tabular}{|c|c|c|c|c|c|}
\hline \multirow[t]{2}{*}{ Factor } & \multirow[t]{2}{*}{ Variable } & \multirow[t]{2}{*}{ Total $(n=153)$} & \multicolumn{2}{|c|}{ PLEE } & \multirow[t]{2}{*}{$p$-Value } \\
\hline & & & Present $(n=26)$ & Absent $(\mathrm{n}=127)$ & \\
\hline \multicolumn{6}{|l|}{ Post-operative complications ( $\geq$ grade II*) } \\
\hline \multirow[t]{3}{*}{ Complication related to anastomosis } & Stenosis & $2(1.3 \%)$ & $1(3.7 \%)$ & $1(0.8 \%)$ & 0.312 \\
\hline & Leakage & $2(1.3 \%)$ & $1(3.7 \%)$ & $1(0.8 \%)$ & 0.312 \\
\hline & Bleeding & $1(0.7 \%)$ & $1(3.7 \%)$ & 0 & 0.170 \\
\hline Pancreatic fistula & & $9(5.9 \%)$ & $4(14.8 \%)$ & $5(4.0 \%)$ & 0.046 \\
\hline Intraabdominal abscess & & $4(2.6 \%)$ & $1(3.7 \%)$ & $3(2.4 \%)$ & 0.529 \\
\hline Postoperative hemorrhage & & $2(1.3 \%)$ & 0 & $2(1.6 \%)$ & 1.000 \\
\hline Atrial fibrillation & & $3(2.0 \%)$ & $1(3.7 \%)$ & $2(1.6 \%)$ & 0.430 \\
\hline
\end{tabular}

PLEE, Postoperative liver enzyme elevation. *According to the Clavien-Dindo classification of surgical complications.

progression-free survival (100\% vs. 98.5\%, $p=0.636)$. During the follow-up period, no lymph node recurrences within the dissected area were observed in the patients that underwent ALHA preserving lymphadenectomy.

\section{Discussion}

The following novel findings were observed in this study. First, liver retraction using the NLR and ALHA ligation were independent risk factors for PLEE after LG for gastric cancer. Second, there were no lymph node recurrences within the dissected area in the patients that underwent ALHA preserving lymphadenectomy.

A long operation time was not an independent risk factor for PLEE in this study. Longer operation times are often accompanied with longer durations of $\mathrm{CO}_{2}$ pneumoperitoneum and liver retraction. Previous reports found that the decreased portal blood flow resulting from the increased intra-abdominal pressure caused by the $\mathrm{CO}_{2}$ pneumoperitoneum was a possible cause of PLEE after LG and that the pneumoperitoneal pressure was associated with the degree of liver function abnormality $(11,12)$. However, taking our results into consideration, the major cause of PLEE might be direct liver damage due to retraction by an NLR and ALHA ligation rather than the $\mathrm{CO}_{2}$ pneumoperitoneum.

When performing either the gastrectomy or lymphadenectomy during LG for gastric cancer, effective liver retraction is necessary to ensure an adequate and safe operative field. Recent studies have suggested that mechanical liver retraction could be a major cause of focal hepatic injury, resulting in PLEE (6). Various liver retraction methods, such as the NLR (7), the Penrose drain $(13,14)$, the SD $(15,16)$, the triangle-suture $(17)$, and the organ retractor $(18,19)$ have been reported; however, the optimal approach to prevent postoperative liver damage is still debatable. Use of the NLR has rapidly and widely spread due to its ease of insertion and considerable variability in retraction direction. However,
Table V. A multivariate analysis to identify the risk factors of postoperative liver enzyme elevation.

\begin{tabular}{lccc}
\hline Factors & \multicolumn{3}{c}{ Multivariate analysis } \\
\cline { 2 - 4 } & Odds ratio & $95 \% \mathrm{CI}$ & $p$-Value \\
\hline BMI & 1.09 & $0.92-1.28$ & 0.328 \\
$\begin{array}{l}\text { Preoperative liver disease } \\
\quad \text { Present } v s \text {. Absent) }\end{array}$ & 4.22 & $0.95-18.90$ & 0.059 \\
$\begin{array}{l}\text { Operation time } \\
\text { Liver retraction method } \\
\quad \text { SD } v \text { s. NLR) }\end{array}$ & 1.01 & $1.00-1.01$ & 0.179 \\
ALHA (Ligation $v s$. & 0.20 & $0.07-0.58$ & 0.003 \\
$\quad$ Absence/Preservation) & 2.76 & $1.04-7.35$ & 0.042 \\
\hline
\end{tabular}

BMI, Body mass index; SD, silicone disc; NLR, Nathanson liver retractor; ALHA, aberrant left hepatic artery.

retraction-related severe postoperative liver lobe necrosis has been reported (20). Whichever method is adopted, the method that causes prolonged congestion in the liver should be avoided. Accordingly, using the SD seems to be more amenable to prevention of PLEE. Alternatively, when using the NLR, it is necessary to avoid retracting the same site for long periods of time (for example, repositioning the retractor every 30 minutes) (21).

An ALHA is the most common variant arising from the LGA (22). Ligation of the ALHA has been reported to cause postoperative liver dysfunction (6). During radical lymphadenectomy, the LGA should be ligated at its origin. When the root of the LGA is ligated, the ALHA is also sacrificed if present. The occurrence of fatal postoperative liver failure (23) and other lethal complications, including left hepatic lobe necrosis $(24,25)$, after ALHA ligation has been reported. An ALHA can be classified as "replaced" or "accessory". Generally, a thick ALHA is recognized as "replaced", while a thin ALHA is recognized as "accessory" during surgery. Kim et 
al. (26) suggested that an ALHA arising from a large LGA with a diameter greater than $5 \mathrm{~mm}$ should be preserved during LG to prevent immediate postoperative liver dysfunction. It has been reported that ligation of a thin ALHA does not cause severe liver damage after surgery (27). It is important to consider whether the ALHA can be classified as either "replaced" or "accessory" before ligation based on the preoperative CT examination and intraoperative findings. There was no difference in the oncological outcomes of lymph node dissection around the LGA between the patients who underwent ALHA preserving lymphadenectomy and others in our study. Similar results have been previously reported by Shinohara et al. (28). Further studies involving a large number of patients may be needed to confirm whether ALHA preserving lymphadenectomy around the LGA is feasible from the perspective of curing gastric cancer.

This study has the following limitations. First, the number of patients analyzed in this study was relatively small as it was a single institution retrospective study. Second, the effect of ALHA ligation on postoperative liver function in patients with severe liver dysfunction is still unknown since all patients in this study were classified as Child-Pugh grade A. Third, the effect of ALHA preserving lymphadenectomy on long-term prognosis was not sufficiently evaluated.

In conclusion, liver retraction using the NLR and ligation of an ALHA were recognized as independent risk factors for PLEE after LG for gastric cancer. Liver retraction with the SD during LG was found to be a safer method that is less likely to cause postoperative liver dysfunction. Further investigations are needed to determine the impact of ALHA preserving lymphadenectomy around the LGA on long-term prognosis.

\section{Conflicts of Interest}

The Authors declare that they have no competing interests for this study.

\section{Authors' Contributions}

All of the Authors have read and approved the manuscript. AS was involved in the conceptualization. AS, KSa, KSh and HS edited the manuscript. AS, KSa, KK, NN, YU, KH, MSa, KO and MSo collected the patient data. AS and KSa analyzed the patient data. AS, KSa, TF, $\mathrm{MF}$ and $\mathrm{HN}$ performed the operation and managed the perioperative course. KSh and HS approved the final submission of the manuscript.

\section{Acknowledgements}

The Authors would like to thank Editage (www.editage.com) for English language editing.

\section{References}

1 Kitano S, Shiraishi N, Uyama I, Sugihara K and Tanigawa N; Japanese Laparoscopic Surgery Study Group: A multicenter study on oncologic outcome of laparoscopic gastrectomy for early cancer in Japan. Ann Surg 245(1): 68-72, 2007. PMID: 17197967. DOI: 10.1097/01.sla.0000225364.03133.f8

2 Viñuela EF, Gonen M, Brennan MF, Coit DG and Strong VE: Laparoscopic versus open distal gastrectomy for gastric cancer: a meta-analysis of randomized controlled trials and high-quality nonrandomized studies. Ann Surg 255(3): 446-456, 2012. PMID: 22330034. DOI: 10.1097/SLA.0b013e31824682f4

3 Katai H, Mizusawa J, Katayama H, Takagi M, Yoshikawa T, Fukagawa T, Terashima M, Misawa K, Teshima S, Koeda K, Nunobe S, Fukushima N, Yasuda T, Asao Y, Fujiwara Y and Sasako M: Short-term surgical outcomes from a phase III study of laparoscopy-assisted versus open distal gastrectomy with nodal dissection for clinical stage IA/IB gastric cancer: Japan Clinical Oncology Group Study JCOG0912. Gastric Cancer 20(4): 699708, 2017. PMID: 27718137. DOI: 10.1007/s10120-016-0646-9

4 Etoh T, Shiraishi N, Tajima M, Shiromizu A, Yasuda K, Inomata $\mathrm{M}$ and Kitano S: Transient liver dysfunction after laparoscopic gastrectomy for gastric cancer patients. World J Surg 31(5): 1115-1120, 2007. PMID: 17426897. DOI: 10.1007/s00268-0070237-3

5 Tsuboi S, Kitano S, Yoshida T, Bandoh T, Ninomiya K and Baatar D: Effects of carbon dioxide pneumoperitoneum on hemodynamics in cirrhotic rats. Surg Endosc 16(8): 1220-1225, 2002. PMID: 11984669. DOI: 10.1007/s00464-001-9163-x

6 Jeong GA, Cho GS, Shin EJ, Lee MS, Kim HC and Song OP: Liver function alterations after laparoscopy-assisted gastrectomy for gastric cancer and its clinical significance. World J Gastroenterol 17(3): 372-378, 2011. PMID: 21253398. DOI: 10.3748/wjg.v17.i3.372

7 Kitajima T, Shinohara H, Haruta S, Momose K, Ueno M and Udagawa $\mathrm{H}$ : Prevention of transient liver damage after laparoscopic gastrectomy via modification of the liver retraction technique using the Nathanson liver retractor. Asian J Endosc Surg 8(4): 413-418, 2015. PMID: 26042554. DOI: 10.1111/ ases. 12200

8 Dindo D, Demartines $\mathrm{N}$ and Clavien PA: Classification of surgical complications: a new proposal with evaluation in a cohort of 6336 patients and results of a survey. Ann Surg 240(2): 205-213, 2004. PMID: 15273542. DOI: 10.1097/01.sla. 0000133083.54934.ae

9 Oki E, Sakaguchi Y, Hiroshige S, Kusumoto T, Kakeji Y and Maehara Y: Preservation of an aberrant hepatic artery arising from the left gastric artery during laparoscopic gastrectomy for gastric cancer. J Am Coll Surg 212(5): e25-27, 2011. PMID: 21398157. DOI: 10.1016/j.jamcollsurg.2011.01.009

10 Kanda Y: Investigation of the freely available easy-to-use software 'EZR' for medical statistics. Bone Marrow Transplant 48(3): 452-458, 2013. PMID: 23208313; DOI: 10.1038/bmt. 2012.244

11 Gutt CN, Oniu T, Mehrabi A, Schemmer P, Kashfi A, Kraus T and Büchler MW: Circulatory and respiratory complications of carbon dioxide insufflation. Dig Surg 21(2): 95-105, 2004. PMID: 15010588 . DOI: 10.1159/000077038

12 Hasukić S: Postoperative changes in liver function tests: randomized comparison of low- and high-pressure laparoscopic cholecystectomy. Surg Endosc 19(11): 1451-1455, 2005. PMID: 16206003. DOI: $10.1007 / \mathrm{s} 00464-005-0061-5$

13 Sakaguchi Y, Ikeda O, Toh Y, Aoki Y, Harimoto N, Taomoto J, Masuda T, Ohga T, Adachi E and Okamura T: New technique 
for the retraction of the liver in laparoscopic gastrectomy. Surg Endosc 22(11): 2532-2534, 2008. PMID: 18320277. DOI: 10.1007/s00464-008-9801-7

14 Shinohara T, Kanaya S, Yoshimura F, Hiramatsu Y, Haruta S, Kawamura Y, Giacopuzzi S, Fujita T and Uyama I: A protective technique for retraction of the liver during laparoscopic gastrectomy for gastric adenocarcinoma: using a Penrose drain. J Gastrointest Surg 15(6): 1043-1048, 2011. PMID: 20824387. DOI: $10.1007 / \mathrm{s} 11605-010-1301-0$

15 Takemura M, Ikebe T, Mayumi K, Nishioka T and Hori T: A novel liver retraction technique for lateral lobe of the liver during laparoscopic surgery using silicone disk. J Laparoendosc Adv Surg Tech A 21(8): 729-732, 2011. PMID: 21780913. DOI: 10.1089/lap.2011.0161

16 Saeki H, Oki E, Kawano H, Ando K, Ida S, Kimura Y, Morita M, Kusumoto T, Ikeda T and Maehara Y: Newly developed liver-retraction method for laparoscopic gastric surgery using a silicone disc: the $\phi$-shaped technique. J Am Coll Surg 216(5): e43-46, 2013. PMID: 23535162. DOI: 10.1016/j.jamcollsurg. 2013.02.005

17 Lee IS, Kim TH, Yook JH, Kim HS, Kim BS and Kim BS: A triangle method: simple suture retraction for the left lobe of the liver during laparoscopic gastric surgery. J Laparoendosc Adv Surg Tech A 22(10): 989-991, 2012. PMID: 23231508. DOI: 10.1089/lap.2012.0314

18 Yoshikawa K, Shimada M, Higashijima J, Nakao T, Nishi M, Takasu C, Kashihara H and Eto S: Combined liver mobilization and retraction: A novel technique to obtain the optimal surgical field during laparoscopic total gastrectomy. Asian J Endosc Surg 9(2): 111-115, 2016. PMID: 26679094. DOI 10.1111/ases.12271

19 Ushimaru Y, Omori T, Fujiwara Y, Shishido Y, Yanagimoto Y, Sugimura K, Yamamoto K, Moon JH, Miyata H, Ohue M and Yano M: A novel liver retraction method in laparoscopic gastrectomy for gastric cancer. Surg Endosc 33(6): 1828-1836, 2019. PMID: 30284022. DOI: 10.1007/s00464-018-6461-0

20 Tamhankar AP, Kelty CJ and Jacob G: Retraction-related liver lobe necrosis after laparoscopic gastric surgery. JSLS 15(1): 117121, 2011. PMID: 21902957. DOI: 10.4293/108680811X 13022985131651

21 Hiramatsu K, Aoba T, Kamiya T, Mohri K and Kato T: Novel use of the Nathanson liver retractor to prevent postoperative transient liver dysfunction during laparoscopic gastrectomy. Asian J Endosc Surg 13(3): 293-300, 2020. PMID: 31389200. DOI: $10.1111 /$ ases.12735
22 Weiglein AH: Variations and topography of the arteries in the lesser omentum in humans. Clin Anat 9(3): 143-150, 1996. PMID: 8740472. DOI: 10.1002/(SICI)1098-2353(1996)9:3<143 :AID-CA1>3.0.CO;2-H

23 Huang CM, Chen QY, Lin JX, Zheng CH, Li P, Xie JW, Wang JB and Lu J: Short-term clinical implications of the accessory left hepatic artery in patients undergoing radical gastrectomy for gastric cancer. PLoS One 8(5): e64300, 2013. PMID: 23717589. DOI: $10.1371 /$ journal.pone. 0064300

24 Lurie AS: The significance of the variant left accessory hepatic artery in surgery for proximal gastric cancer. Arch Surg 122(6): 725-728, 1987. PMID: 3579588. DOI: 10.1001/archsurg. 1987.01400180107021

25 Hemming AW, Finley RJ, Evans KG, Nelems B and Fradet G: Esophagogastrectomy and the variant left hepatic artery. Ann Thorac Surg 54(1): 166-168, 1992. PMID: 1610235. DOI: 10.1016/0003-4975(92)91173-7

26 Kim J, Kim SM, Seo JE, Ha MH, An JY, Choi MG, Lee JH, Bae JM, Kim S, Jeong WK and Sohn TS: Should an aberrant left hepatic artery arising from the left gastric artery be preserved during laparoscopic gastrectomy for early gastric cancer treatment? J Gastric Cancer 16(2): 72-77, 2016. PMID: 27433391. DOI: $10.5230 /$ jgc.2016.16.2.72

27 Okano S, Sawai K, Taniguchi H and Takahashi T: Aberrant left hepatic artery arising from the left gastric artery and liver function after radical gastrectomy for gastric cancer. World J Surg 17(1): 70-73; discussion 74, 1993. PMID: 8447143. DOI: 10.1007/BF01655708

28 Shinohara T, Ohyama S, Muto T, Yanaga K and Yamaguchi T: The significance of the aberrant left hepatic artery arising from the left gastric artery at curative gastrectomy for gastric cancer. Eur J Surg Oncol 33(8): 967-971, 2007. PMID: 17418995. DOI: 10.1016/j.ejso.2007.02.030

Received December 25, 2020

Revised January 15, 2021

Accepted January 21, 2021 